\title{
Rapid diagnostic tests for molecular surveillance of Plasmodium falciparum malaria -assessment of DNA extraction methods and field applicability
}

Ulrika Morris ${ }^{1 *}$, Berit Aydin-Schmidt ${ }^{1}$, Delér Shakely ${ }^{1,2}$, Andreas Mårtensson $^{1,3}$, Louise Jörnhagen ${ }^{1}$, Abdullah S Ali ${ }^{4}$, Mwinyi I Msellem ${ }^{4}$, Max Petzold ${ }^{5}$, José P Gil ${ }^{6,7,8}$, Pedro E Ferreira ${ }^{1,9}$ and Anders Björkman ${ }^{1}$

\begin{abstract}
Background: The need for new malaria surveillance tools and strategies is critical, given improved global malaria control and regional elimination efforts. High quality Plasmodium falciparum DNA can reliably be extracted from malaria rapid diagnostic tests (RDTs). Together with highly sensitive molecular assays, wide scale collection of used RDTs may serve as a modern tool for improved malaria case detection and drug resistance surveillance. However, comparative studies of DNA extraction efficiency from RDTs and the field applicability are lacking. The aim of this study was to compare and evaluate different methods of DNA extraction from RDTs and to test the field applicability for the purpose of molecular epidemiological investigations.

Methods: DNA was extracted from two RDT devices (Paracheck-Pf ${ }^{\circledR}$ and SD Bioline Malaria Pf/Pan ${ }^{\circledR}$ ), seeded in vitro with 10-fold dilutions of cultured 3D7 P. falciparum parasites diluted in malaria negative whole blood. The level of $P$. falciparum detection was determined for each extraction method and RDT device with multiple nestedPCR and real-time PCR assays. The field applicability was tested on 855 paired RDT (Paracheck-Pf) and filter paper (Whatman ${ }^{\circledR}$ 3MM) blood samples (734 RDT negative and 121 RDT positive samples) collected from febrile patients in Zanzibar 2010. RDT positive samples were genotyped at four key single nucleotide polymorphisms (SNPs) in pfmdr1 and pfcrt as well as for pfmdr1 copy number, all associated with anti-malarial drug resistance.

Results: The P. falciparum DNA detection limit varied with RDT device and extraction method. Chelex-100 extraction performed best for all extraction matrixes. There was no statistically significant difference in PCR detection rates in DNA extracted from RDTs and filter paper field samples. Similarly there were no significant differences in the PCR success rates and genotyping outcomes for the respective SNPs in the 121 RDT positive samples.
\end{abstract}

Conclusions: The results support RDTs as a valuable source of parasite DNA and provide evidence for RDT-DNA extraction for improved malaria case detection, molecular drug resistance surveillance, and RDT quality control.

Keywords: Plasmodium falciparum, Malaria, Rapid diagnostic test, DNA extraction, Molecular surveillance

\section{Background}

The World Health Organization has recommended the use of malaria rapid diagnostic tests (RDTs) for prompt and accurate parasitological confirmation of Plasmodium falciparum malaria in settings where microscopy services are not available. However, the ability to detect individuals with asymptomatic low density parasitaemia, i.e., below

\footnotetext{
* Correspondence: ulrika.morris@ki.se

${ }^{1}$ Malaria Research, Department of Medicine Solna, Karolinska Institutet, Stockholm, Sweden

Full list of author information is available at the end of the article
}

detection limit of both RDTs and microscopy ( 100 parasites/ $\mu \mathrm{L}$ blood), in low endemic settings has been increasingly acknowledged as a challenge to achieve malaria elimination [1]. In this context there is a need for novel sensitive molecular tools and strategies for improved malaria case detection. Furthermore, molecular tools for monitoring the selection of genotypes associated with anti-malarial drug resistance are critical since they may provide an early warning system of development and spread of tolerance/ resistance to artemisinin-based combination therapy (ACT) before clinical treatment failures are apparent.

\section{Biomed Central}


The possibility of recovering parasite DNA from RDTs was first shown by Veron et al. [2]. Thereafter, two additional methods of DNA extraction from RDTs have been published [3,4] suggesting that RDTs are a reliable source for parasite DNA preservation. This provides an opportunity for improved molecular surveillance and RDT quality control. However, and importantly, comparative studies on the efficiency of the published DNA extraction methods from RDTs are lacking. This is critical since there is evidence that the efficiency of DNA extraction may be highly influenced by choice of extraction matrix and method [3-6]. Furthermore, comprehensive studies are needed to investigate whether wide-scale collection of RDTs can provide the basis for modern molecular surveillance of malaria, including both improved malaria case detection and anti-malarial drug resistance genotyping.

The aims of this study were, therefore, to evaluate two published DNA extraction methods, in comparison with a previously unpublished, high-throughput method (Ferreira P E, unpublished data), and to assess the field applicability of RDT-DNA extraction for molecular surveillance, in comparison to DNA extraction from filter paper.

\section{Methods}

\section{RDT-DNA extraction methods}

Three DNA extraction methods from RDTs were evaluated: 1) A simple elution method [3]; 2) Chelex-100 extraction [4]; and, 3) a previously unpublished method following a modified version of the protocol "isolation of DNA from fresh or frozen whole blood" employing an ABI PRISM 6100 Nucleic Acid PrepStation ${ }^{\mathrm{TM}}$ and NucPrep reagents (Applied Biosystems, USA) (Ferreira P E, unpublished data). In brief, for the third method, the biological samples were lysed in three-fold volume of NucPrep reagents. The lysate mixture was incubated for 1 h (instead of $10 \mathrm{~min})$ at $58^{\circ} \mathrm{C}$, and the lysed samples were incubated at $4^{\circ} \mathrm{C}$ overnight before preforming the extraction (as previously reported) [7]. On day two, the solid material was separated from the lysate by passing the content through a $5 \mathrm{~mL}$ syringe. The full lysate was flowed through one column per sample in a DNA purification tray II (Applied Biosystems, USA) by three consecutive loadings. DNA washing was performed as recommended by the manufacturer. Incubation with DNA elution solution 1 was increased from three to five minutes. The final DNA containing elution volume was $200 \mu \mathrm{L}$ for ABI extraction, $50 \mu \mathrm{L}$ in the simple elution method and $\sim 190 \mu \mathrm{L}$ in the Chelex-100 extraction (after deduction of 5\% Chelex-100 from a total volume of $200 \mu \mathrm{L}$ ).

\section{RDT devices}

DNA extraction was compared from two RDT devices of clinical importance in Zanzibar: Paracheck- $\mathrm{Pf}^{\circledR}$ (Orchid Biomedical Systems, Goa, India) and SD-Bioline Malaria
Ag P.f/Pan ${ }^{\circledR}$ (Standard Diagnostic, Inc, USA). ParacheckPf has been widely used in sub-Saharan Africa, and was the first RDT to be implemented in Zanzibar in 2006. Zanzibar has recently changed to SD-Bioline P.f/Pan as this test also detects species other than P. falciparum.

\section{Plasmodium falciparum in vitro samples and analysis}

Both RDT devices were seeded according to the manufacturers' instructions with $5 \mu \mathrm{L}$ of 10 -fold serial dilutions of laboratory cultured 3D7 P. falciparum (200,000-0.02 parasites $/ \mu \mathrm{L})$ as well as with malaria negative whole blood (negative control). For comparison, Whatman ${ }^{\circledR} 3 \mathrm{MM}$ filter paper was seeded in parallel with $5 \mu \mathrm{L}$ (approximately equivalent to one $3-\mathrm{mm}$ punch) of the serial dilution. Parasite cultures and malaria negative whole blood were lysed by freeze-thawing prior to serial dilution.

The RDTs and filter papers were allowed to air dry for a minimum of 16 hours at room temperature $\left(20^{\circ} \mathrm{C}\right)$, whereafter RDT cassettes were opened using a thin metal spatula. The nitrocellulose strip was held at the buffer pad with forceps and cut into $3 \times 3 \mathrm{~mm}$ pieces using scissors. In between each sample, forceps and scissors were washed in $70 \%$ ethanol and dried on clean tissue paper, to minimise cross-contamination during sample preparation. RDT preparation was in accordance with the worldwide antimalarial resistance network (WWARN) guidelines, with minor modifications [8]. DNA extraction was compared from four different RDT fragments (Figure 1), all including the proximal third of the nitrocellulose strip that has been reported to generate best results upon DNA extraction [3]. DNA was extracted using the three methods described above.

The $P$. falciparum DNA detection limits were determined using three PCR techniques: $18 \mathrm{~S}$ ribosomal DNA (rDNA) nested PCR [9], cytochrome b nested PCR [10], and $18 \mathrm{~S}$ rDNA probe-based real-time PCR [11]. The same volume of DNA was used from each extraction method (2-5 $\mu \mathrm{L}$ depending on PCR). The P. falciparum detection limits were determined as the lowest consecutive positive sample in the dilution series.

\section{Field study sampling}

The field samples were collected during an RDT effectiveness study conducted in 12 public health facilities, six each in North A and Micheweni districts, Zanzibar, May-July 2010 (Shakely et al., submitted). Febrile patients were tested for P. falciparum malaria with Paracheck-Pf. In parallel approximately $100 \mu \mathrm{L}$ of blood was spotted onto Whatman 3MM filter paper. Paired RDT and filter paper samples were available from 121 RDT positive and 734 RDT negative patients. Informed consent was obtained from enrolled patients or parent/guardians of children. The study was conducted in accordance with the Declaration of Helsinki [12] and Good Clinical Practice [13]. The study is registered as NCT01002066. Ethical approvals 


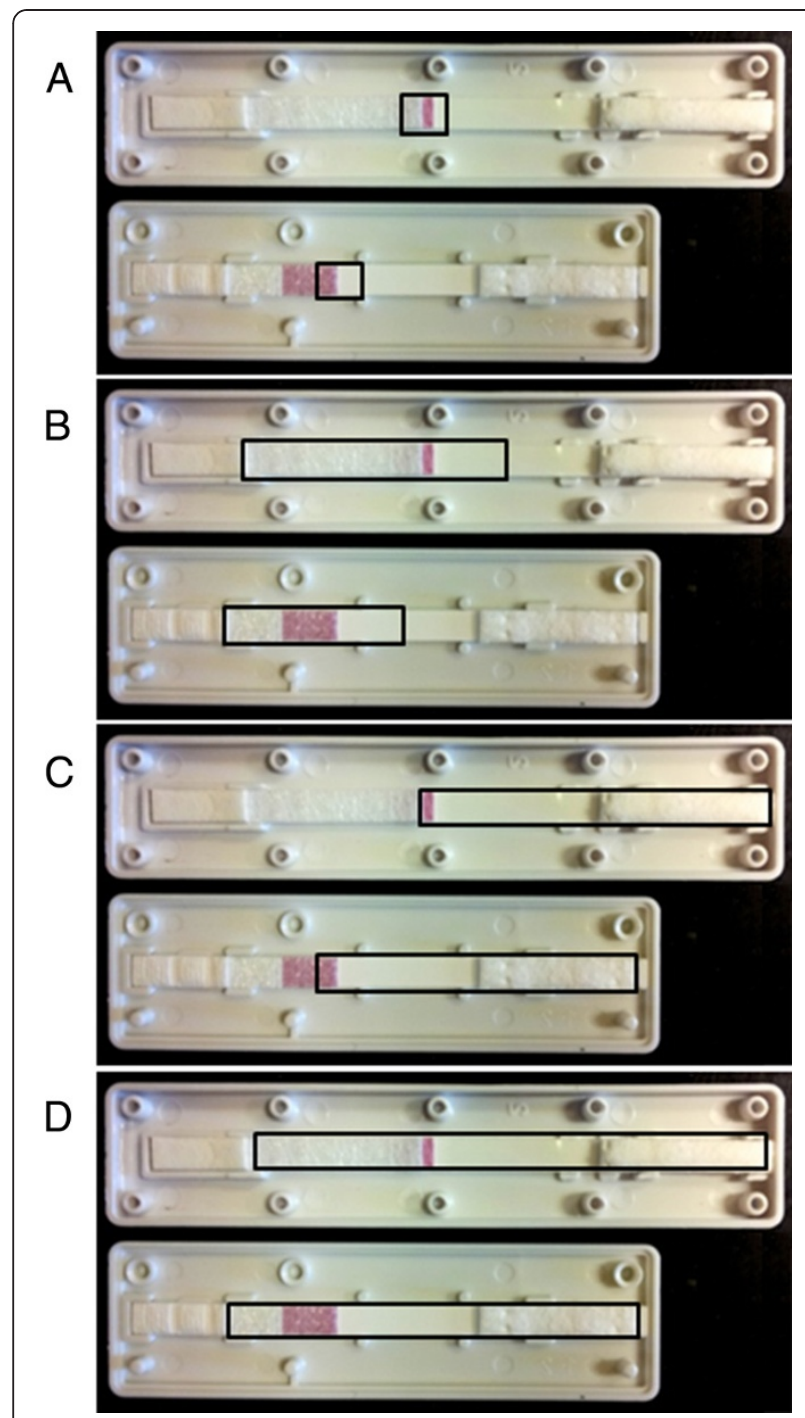

Figure 1 RDT fragments used for DNA extraction. Each panel shows Paracheck-Pf (top) and SD-Bioline Malaria Ag P.f/Pan (bottom). The RDTs are orientated with the buffer pad and sample site to the left (proximal end), and the absorption pad to the right (distal end). The fragments used for extraction are outlined by the black boxes A) $1 \mathrm{~cm}$ B) Proximal C) Distal D) Whole.

were obtained from the ethical committee in Zanzibar (ZAMREC/ST/0021/09) and the Regional Ethics Committee in Stockholm, Sweden (2009/387-31). All samples were stored at room temperature with desiccants until the time of DNA extraction. Samples were transported to Karolinska Institutet, Sweden, August 2010, where DNA extraction from RDT and filter paper samples was conducted in parallel within six months after sample collection.

\section{Field sample analysis}

DNA was extracted from the paired RDT and filter paper field samples $(\mathrm{N}=855)$ using the ABI PRISM 6100 Nucleic Acid PrepStation $^{\mathrm{TM}}$ method. DNA was extracted from the distal two thirds (Figure 1C) of the RDT strip, containing $\sim 5 \mu \mathrm{L}$ blood, as described above, and from three 3-mm punches of filter paper, containing $\sim 15 \mu \mathrm{L}$ blood, as described previously [7].

RDT negative samples $(\mathrm{N}=734)$ were screened using an $18 \mathrm{~S}$ rDNA real-time PCR assay, that detects all five species of Plasmodium [14]. Samples were pooled two by two in 384 well plates. Each PCR was performed twice at different time points. Pools with a single Cycle threshold $(\mathrm{Ct})$ value $<40$, or a $\mathrm{Ct}$ average $<42$ were selected for multiplex species identification for P. falciparum, Plasmodium vivax, Plasmodium ovale and Plasmodium malariae. Samples were considered PCR positive if positive in the species identification analysis.

Single nucleotide polymorphisms (SNPs) in pfcrt K76T, pfindr1 N86Y, Y184F and D1246Y were analysed with previously described PCR-RFLP methods in all RDT positive samples $(\mathrm{N}=121)$ [15-17]. An infection was defined as mixed when both alleles were present at a particular locus. Pfmdr1 copy number was determined by the comparative $\Delta \Delta \mathrm{Ct}$ method following a TaqMan probe-based real-time PCR [18]. Samples were considered PCR positive if positive in at least one PCR.

All PCRs were run in parallel on RDT and filter paper extracted DNA.

\section{Statistical analysis}

SNP genotyping outcomes were compared between RDT and filter paper extracted DNA by kappa analysis (k). The SNP and haplotype prevalences were analysed and published elsewhere [17]. The spread of $\mathrm{Ct}$ values below

Table 1 Sensitivity of RDT-DNA extraction methods in in vitro cultured parasites

\begin{tabular}{|c|c|c|c|}
\hline RDT Fragment & Simple elution & Chelex-100 & $A B I$ \\
\hline \multicolumn{4}{|l|}{ Paracheck-Pf } \\
\hline $1 \mathrm{~cm}$ & $\S$ & 2 & 200 \\
\hline Proximal & NA & 20 & 200 \\
\hline Distal & NA & NA & 20 \\
\hline Whole & NA & NA & 20 \\
\hline \multicolumn{4}{|c|}{ SD-Bioline Malaria P.f/Pan } \\
\hline $1 \mathrm{~cm}$ & 2 & 2 & 20 \\
\hline Proximal & NA & 2 & 20 \\
\hline Distal & NA & NA & 20 \\
\hline Whole & NA & NA & 20 \\
\hline \multicolumn{4}{|l|}{ Filter paper } \\
\hline $5 \mu \mathrm{L}$ blood spot & 200 & 2 & 200 \\
\hline \multicolumn{4}{|c|}{$\begin{array}{l}\text { Lowest achieved parasite detection levels (parasites/ } \mu \mathrm{L} \text { ) for DNA extraction } \\
\text { from Paracheck-Pf, SD-Bioline Malaria P.f/Pan and from } 5 \mu \mathrm{L} \text { blood spotted on } \\
\text { filter paper. } \\
\S=\text { Not estimated due to negative results. } \\
\mathrm{NA}=\text { Not applicable, the size of the RDT fragment used for extraction was } \\
\text { limited by the extraction volume. }\end{array}$} \\
\hline
\end{tabular}


Table 2 PCR success rates and agreement of genotyping outcomes in field samples

\begin{tabular}{llll}
\hline & RDT PCR success rates $\mathbf{N}=\mathbf{1 2 1}$ (\%; Cl 95\%) & Filter paper PCR success rates $\mathbf{N}=\mathbf{1 2 1}$ (\%; Cl 95\%) & Kappa value \\
\hline Pfcrt K76T & $114(94.2 ; 89.9-98.5)$ & $104(86.0 ; 79.6-92.3)$ & 0.72 \\
Pfmdr1 N86Y & $112(92.6 ; 87.8-97.4)$ & $109(90.1 ; 84.6-95.5)$ & 0.85 \\
Pfmdr1 Y184F & $110(90.9 ; 85.7-96.2)$ & $107(88.4 ; 82.6-94.3)$ & 0.74 \\
Pfmdr1 D1246Y & $113(93.4 ; 88.8-97.9)$ & $107(88.4 ; 82.6-94.3)$ & 0.77 \\
Pfmdr1 copy number & $84(69.4 ; 61.0-77.8)$ & $77(63.6 ; 54.9-72.4)$ & - \\
\hline
\end{tabular}

Analyses of single nucleotide polymorphisms and pfmdr1 gene copy numbers associated with anti-malarial drug resistance, from RDT and filter paper extracted DNA collected from 121 RDT positive field samples.

the cut-off of Ct 35, in the TaqMan probe-based realtime PCR for determining pfindr1 copy number, were compared by Wilcoxon rank-sum test, as there were many incomplete pairs. All calculations were done with Stata/SE 12.0, StataCorp LP USA. Statistical significance was defined as $\mathrm{p}<0.05$.

\section{Results}

In vitro cultured parasites - sensitivity of RDT-DNA extraction methods

The P. falciparum DNA detection limit varied with RDT device and extraction method (Table 1). When following the respective protocols, Chelex-100 extraction preformed best for both RDT devices as well as for extraction from filter paper, with a detection limit of two parasites $/ \mu \mathrm{L}$. The ABI extraction method had a 10-fold higher detection limit of 20 parasites $/ \mu \mathrm{L}$. DNA extraction was generally more efficient from SD-Bioline Malaria Ag P.f/Pan than from Paracheck-Pf. The simple elution method was unsuccessful for DNA extraction from Paracheck-Pf. Increasing the size of the nitrocellulose strip fragment (as seen in Figure 1) did not improve the level of detection. The method of P. falciparum detection influenced the detection limit by one to two log units (see Additional file 1). DNA extraction from RDTs was generally equal to or better than DNA extraction from an equal volume $(5 \mu \mathrm{L})$ of blood spotted on filter paper.

\section{Field samples - parasite detection and drug resistance genotyping}

There was no significant difference in PCR detection rates in DNA extracted from RDTs and filter paper. Out of 855 paired RDT and filter paper field samples, 118 (13.8\%; CI 95\% 11.4-16.2\%) were PCR positive in both groups of samples $(\kappa=0.94)$. Among the RDT negative field samples $(\mathrm{N}=734)$, three (0.4\%; CI 95\% $0.0-0.9 \%)$ and six (0.8\%; CI 95\% 0.1-1.5\%) were PCR positive from RDT and filter paper extracted DNA, respectively $(\kappa=0.44)$. Among the 121 RDT positive field samples, 115 (95.0\%; CI 95\% 91.1-99.0\%) and 112 (92.6\%; CI 95\% 87.8-97.4\%) were PCR positive $(\kappa=0.50)$. No observed difference was found in the ability to detect low density

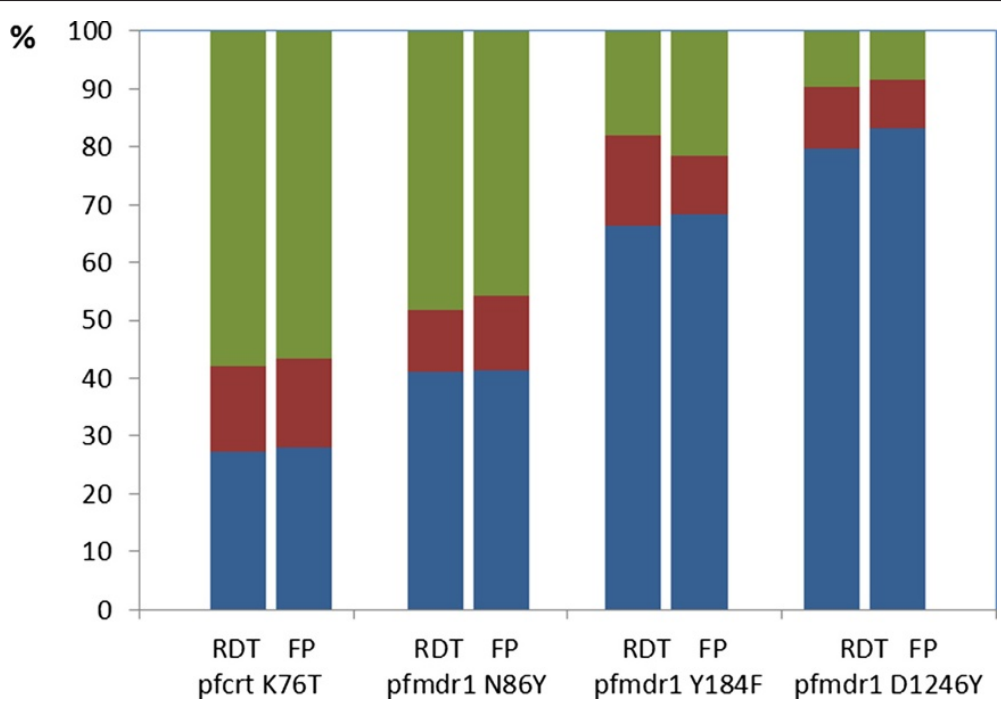

Figure 2 Genotyping outcomes for RDT and filter paper extracted DNA at four key drug-resistance associated SNPs. Stacked bar graph comparing the genotyping outcomes for RDT and filter paper extracted DNA for pfcrt K76T, pfmdr1 N86Y, pfmdr1 Y184F and pfmdr1 D1246Y. Blue colour represents pfcrt K76, pfmdr1 N86, Y184 and D1246, whereas red represents mixed infections, and green represents pfcrt 76T, pfmdr1 86Y, $184 \mathrm{~F}$ and $1246 \mathrm{Y}$, respectively. 
parasitaemia $(<100$ parasites $/ \mu \mathrm{L})$, although the numbers were too small to allow for statistical analysis (12 PCR positives in both RDT and filter paper extracted DNA).

There were no significant differences in PCR success rates and genotyping outcomes for the respective SNPs in the 121 RDT positive samples (Table 2). Furthermore, there was no difference between RDT and filter paper extracted DNA in the overall ability to detect mixed infections (Figure 2). Similarly, no statistically significant differences in the distribution of real-time PCR Ct values below Ct 35 from RDT and filter paper extracted DNA were observed $\left(\mathrm{P}_{\mathrm{FAM}}=0.10 ; \mathrm{P}_{\mathrm{VIC}}=0.24\right)$. No sample contained multiple $p f m d r 1$ copy number.

\section{Discussion}

This is to date the most comprehensive comparative study of DNA extraction efficiency from malaria RDTs and assessment of the field applicability of RDT-DNA extraction for molecular surveillance, including detection of infections and key genetic markers associated with anti-malarial drug resistance.

DNA extraction efficiency from in vitro cultured $P$. falciparum varied with RDT device and extraction method. The same level of parasite detection as seen in previous publications was not achieved in this study $[3,4]$. Different designs of RDT devices affected the DNA extraction efficiency. In particular, DNA recovery from Paracheck-Pf was unsuccessful when employing the simple elution method, supporting as previously reported that plastic seals covering the nitrocellulose strip hamper DNA recovery [3].

The cost, time, final template volume and the purpose for DNA extraction should be considered when choosing extraction method. Although simple elution is the cheapest and fastest alternative, it is a crude method of DNA extraction and its use may be limited by RDT design and choice of PCR [3]. Chelex-100 is relatively inexpensive. The higher sensitivity observed with Chelex-100 extraction indicates that this method is particularly suitable for low density parasitaemia in low endemic settings. However, the Chelex-100 method is moderately labour-intensive and the DNA may be of lower quality than DNA extracted with commercially available column-based extraction kits [6]. Another concern is the storage capacity of Chelex-100 extracted DNA, which is thought to be more susceptible to DNA degradation during sample freeze-thawing [19]. Conversely, ABI extraction is a high throughput method providing high quality DNA, but at a substantial cost and requiring specialised equipment. This method had a higher $P$. falciparum detection level when compared with Chelex100, perhaps explained by loss of DNA on the column. However, this did not appear to have influenced the field sample results (see below). Thus, ABI extraction could be suitable for analyses of RDT positive, symptomatic malaria patients enrolled in clinical trials. The final DNA containing volume is also important to take into consideration, as the concentration of the DNA will affect the parasite detection limits.

In the field analysis, RDTs provided DNA of equal quality as filter papers, suggesting that RDTs are a valuable alternative to filter paper for DNA storage in the field. High PCR success rates were obtained from DNA extracted from RDTs, for key loci in $p f c r t$ and $p f m d r 1$ associated with anti-malarial drug resistance. SNP and haplotype prevalences were analysed and discussed elsewhere [17]. Wide scale collection of used RDTs is currently being implemented as an integral part of molecular surveillance of malaria in Zanzibar.

Increased deployment of RDTs in health care facilities and cross-sectional surveys facilitates passive and active collection of biological material for molecular surveillance. The advantages of using RDTs for DNA storage include reducing invasive procedures in the field. RDTs require just one finger prick for both malaria case detection and preservation of biological material. DNA storage on filter papers, on the other hand, requires an initial finger prick for malaria case detection by RDT or microscopy, followed by a second finger prick, for individuals with a positive diagnosis for collection of blood on filter paper. Multiple blood sampling can especially be problematic in small children and may increase the risk of mixing/miss-labelling of samples during collection. RDTs are also easily stored and have either a plastic or cardboard case that protects against cross-contamination. A disadvantage of RDT-DNA extraction is the limited amount of biological material $(5-15 \mu \mathrm{L}$ blood). This makes RDT-DNA extraction a "one shot operation" with no possibilities for re-extraction, unlike filter paper sampling where a larger amount of blood is usually collected $(50-100 \mu \mathrm{L})$.

\section{Conclusions}

The results support RDTs as a valuable source of parasite DNA and provide evidence for RDT-DNA extraction for improved malaria case detection, molecular drug resistance surveillance, and RDT quality control. However, the purpose of DNA extraction should be considered when choosing which extraction method best suits the type of samples to be analysed.

\section{Additional file}

Additional file 1: Sensitivity of RDT-DNA extraction methods in in vitro cultured parasites. Description: Raw data showing detection levels for the three PCR methods used in the in vitro part of the study.

Competing interests

The authors declare that they have no competing interests. 


\section{Authors' contributions}

PF, UM, BA, AM, JPG and AB conceived and designed the study. DS, ASA and MIM carried out the field work. UM, BA and $L J$ carried out the molecular analyses. UM, BA, LJ, PF, AM and AB analysed the data. MP gave important intellectual input in the statistical analysis. UM drafted the manuscript. All authors read and approved the final manuscript.

\section{Acknowledgements}

We thank the patients and health staff of the different health care centres in Zanzibar for their participation in the clinical studies. We are also grateful to Dr Lisselotte Cnops for important intellectual input on DNA extraction from RDTs. This study was funded by the ACT Consortium through an award from the Bill and Melinda Gates Foundation to the London School of Hygiene and Tropical Medicine; the Swedish International Development Agency (SIDA) [grant number SWE 2009-193]; the Swedish Civil Contingencies Agency (MSB) [grant number 2010-7991]; the Swedish Medical Research Council (VR) [grant number 2009-3785] and Goljes Foundation.

\section{Author details}

${ }^{1}$ Malaria Research, Department of Medicine Solna, Karolinska Institutet, Stockholm, Sweden. ${ }^{2}$ Department of Medicine, Kungälv Hospital, Kungälv, Sweden. ${ }^{3}$ Department of Public Health Sciences, Division of Global Health (IHCAR), Karolinska Institutet, Stockholm, Sweden. ${ }^{4}$ Zanzibar Malaria Control Programme (ZMCP), Ministry of Health, Zanzibar, Tanzania. ${ }^{5}$ Centre for Applied Biostatistics, Sahlgrenska Academy, University of Gothenburg, Gothenburg, Sweden. 'Drug Resistance and Pharmacogenetics Group, Institute of Biotechnology and Bioengineering, Centre of Molecular and Structural Biomedicine, University of Algarve, Faro, Portugal. ' Laboratory of Molecular Anthropology and Health, Department of Anthropology, Binghamton University, Binghamton, NY, USA. ${ }^{8}$ Department of Physiology and Pharmacology, Drug Resistance Unit, Section of Pharmacogenetics, Karolinska Institutet, Stockholm, Sweden. ${ }^{9}$ Department of Protozoology, Institute of Tropical Medicine, Nagasaki University, Nagasaki, Japan.

Received: 21 December 2012 Accepted: 10 March 2013 Published: 21 March 2013

\section{References}

1. Okell LC, Bousema T, Griffin JT, Ouedraogo AL, Ghani AC, Drakeley CJ: Factors determining the occurrence of submicroscopic malaria infections and their relevance for control. Nat Commun 2012, 3:1237.

2. Veron V, Carme B: Recovery and use of Plasmodium DNA from malaria rapid diagnostic tests. AmJTrop Med Hyg 2006, 74:941-943.

3. Cnops L, Boderie M, Gillet P, Van Esbroeck M, Jacobs J: Rapid diagnostic tests as a source of DNA for Plasmodium species-specific real-time PCR. Malar J 2011, 10:67.

4. Ishengoma DS, Lwitiho S, Madebe RA, Nyagonde N, Persson O, Vestergaard LS, Bygbjerg IC, Lemnge MM, Alifrangis M: Using rapid diagnostic tests as source of malaria parasite DNA for molecular analyses in the era of declining malaria prevalence. Malar J 2011, 10:6.

5. Bereczky S, Martensson A, Gil JP, Farnert A: Rapid DNA extraction from archive blood spots on filter paper for genotyping of Plasmodium falciparum. AmJTrop Med Hyg 2005, 72:249-251.

6. Hwang J, Jaroensuk J, Leimanis ML, Russell B, McGready R, Day N, Snounou G, Nosten F, Imwong M: Long-term storage limits PCR-based analyses of malaria parasites in archival dried blood spots. Malar J 2012, 11:339.

7. Dahlstrom S, Veiga MI, Ferreira P, Martensson A, Kaneko A, Andersson B, Bjorkman A, Gil JP: Diversity of the sarco/endoplasmic reticulum $\mathrm{Ca}(2+)$-ATPase orthologue of Plasmodium falciparum (PfATP6). Infect Genet Evol 2008, 8:340-345.

8. Preparation of Rapid Diagnostic Tests (RDTs) for DNA extraction V1.1. http://www.wwarn.org/sites/default/files/MOL06_RDTsForDNAExtraction.pdf.

9. Snounou G, Viriyakosol S, Jarra W, Thaithong S, Brown KN: Identification of the four human malaria parasite species in field samples by the polymerase chain reaction and detection of a high prevalence of mixed infections. Mol Biochem Parasitol 1993, 58:283-292.

10. Steenkeste $N$, Incardona S, Chy S, Duval L, Ekala MT, Lim P, Hewitt S, Sochantha T, Socheat D, Rogier C, Mercereau-Puijalon O, Fandeur T, Ariey F: Towards high-throughput molecular detection of Plasmodium: new approaches and molecular markers. Malar J 2009, 8:86.
11. Kamau E, Tolbert LS, Kortepeter L, Pratt M, Nyakoe N, Muringo L, Ogutu B, Waitumbi JN, Ockenhouse CF: Development of a highly sensitive genusspecific quantitative reverse transcriptase real-time PCR assay for detection and quantitation of Plasmodium by amplifying RNA and DNA of the 18S rRNA genes. J Clin Microbiol 2011, 49:2946-2953.

12. World Medical Association (WMA) Declaration of Helsinki - Ethical Principles for Medical Research Involving Human Subjects. http://www.wma.net/en/ 30publications/10policies/b3/index.html.

13. ICH Good Clinical Practice. http://www.ich.org/products/guidelines.html.

14. Shokoples SE, Ndao M, Kowalewska-Grochowska K, Yanow SK: Multiplexed real-time PCR assay for discrimination of Plasmodium species with improved sensitivity for mixed infections. J Clin Microbiol 2009, 47:975-980.

15. Holmgren G, Hamrin J, Svard J, Martensson A, Gil JP, Bjorkman A: Selection of pfmdr 1 mutations after amodiaquine monotherapy and amodiaquine plus artemisinin combination therapy in East Africa. Infect Genet Evol 2007, 7:562-569.

16. Veiga MI, Ferreira PE, Bjorkman A, Gil JP: Multiplex PCR-RFLP methods for pfcrt, pfmdr1 and pfdhfr mutations in Plasmodium falciparum. Mol Cell Probes 2006, 20:100-104.

17. Froberg G, Jornhagen L, Morris U, Shakely D, Msellem MI, Gil JP, Bjorkman A, Martensson A: Decreased prevalence of Plasmodium falciparum resistance markers to amodiaquine despite its wide scale use as ACT partner drug in Zanzibar. Malar J 2012, 11:321

18. Price RN, Uhlemann AC, Brockman A, McGready R, Ashley E, Phaipun L, Patel R, Laing K, Looareesuwan S, White NJ, Nosten F, Krishna S: Mefloquine resistance in Plasmodium falciparum and increased pfmdr1 gene copy number. Lancet 2004, 364:438-447.

19. Greenspoon SA, Scarpetta MA, Drayton ML, Turek SA: QIAamp spin columns as a method of DNA isolation for forensic casework. J Forensic Sci 1998, 43:1024-1030.

doi:10.1186/1475-2875-12-106

Cite this article as: Morris et al:: Rapid diagnostic tests for molecular surveillance of Plasmodium falciparum malaria -assessment of DNA extraction methods and field applicability. Malaria Journal 2013 12:106.

\section{Submit your next manuscript to BioMed Central and take full advantage of:}

- Convenient online submission

- Thorough peer review

- No space constraints or color figure charges

- Immediate publication on acceptance

- Inclusion in PubMed, CAS, Scopus and Google Scholar

- Research which is freely available for redistribution

Submit your manuscript at www.biomedcentral.com/submit
C BioMed Central 